\title{
Efficiency Analysis of Logistics Centers Dedicated to Retail Type: A Case of a Korean Distribution Company
}

Author(s): Kwangwuk Kim, Dong-Hoon Son, Hwa-Joong Kim

Source: Journal of International Logistics and Trade 2019; 17(1):33-41

Published by: Jungseok Research Institute of International Logistics and Trade, Inha University

DOI: https://doi.org/10.24006/jilt.2019.17.1.033

The Journal of International Logistics and Trade is an official journal published by Jungseok Research Institute of International Logistics and Trade, Inha University, Korea. JILT welcomes manuscripts that advance the practice and science of logistics, trade, and other related fields.

Frequency: Quarterly (March, June, September, December)

Stable URL: https://www.ejilt.org

The Jungseok Research Institute of International Logistics and Trade is a specialized academic research institute representing Inha University and the Inha Foundation in Korea. The institute aims to become a representative institute in Northeast Asia in the research of logistics and trade.

Stable URL: https://jrieng.inha.ac.kr

(C) Copyright. Jungseok Research Institute of International Logistics and Trade.

This is an Open-Access article distributed under the terms of the Creative Commons Attribution NonCommercial License (http://creativecommons.org/licenses/by-nc/4.0/) which permits unrestricted noncommercial use, distribution, and reproduction in any medium, provided the original work is properly cited 


\title{
Journal of
}

\section{International Logistics and Trade}

\section{Efficiency Analysis of Logistics Centers Dedicated to Retail Type: A Case of a Korean Distribution Company}

\author{
Kwangwuk Kimª, Dong-Hoon Son ${ }^{\mathrm{a}}$, Hwa-Joong Kim ${ }^{\mathrm{b} *}$ \\ ${ }^{\text {a }}$ Graduate School of Logistics, Inha University, Korea \\ ${ }^{b}$ Asia Pacific School of Logistics, Inha University, Korea
}

\begin{abstract}
ARTICLE INFO
Article history:

Received 16 March 2019

Accepted 26 March 2019

Keywords:

Multi-channel distribution

Dedicated logistics center

Efficiency analysis

DEA

ABSTRACT

In today's multi-channel distribution environment, it is crucial for the competitiveness of retail stores and companies to improve efficiency of dedicated logistics centers (DLCs) servicing types of retail outlets such as large retail-stores, super supermarkets, and convenient stores. This paper derives efficiency improvement strategies for DLCs through efficiency analyses. To this end, this paper empirically analyzes the efficiency of DLCs by applying DEA (data envelopment analysis) approaches using real data from a Korean distribution company. In detail, this paper analyzes operations, finance, and service efficiencies of DLCs and performs a comparison analysis on the efficiency between DLCs. Finally, this paper discusses the analysis results considering the DLCs' characteristics and derives managerial and operational implications.
\end{abstract}

(C) 2019 Jungseok Research Institute of International Logistics and Trade All rights reserved.

\section{Introduction}

In order to survive in the today's consumer-oriented competitive market, suppliers have introduced a new retail type that focuses on consumer convenience. These are large-scale marts (Mart) like Wal-Mart, and convenience stores (CVS) pursuing high margins by providing time and space benefits, and super supermarkets (SSM) (Ryu, 2010). In the field of logistics, the dedicated logistics center (DLC) is newly emerging compared with existing general purpose logistics centers that provide logistics services to various distribution sectors. DLC is a logistics center that specializes in logistics facilities and services to support specific retail types. E-Mart, Lotte Mart, and Homeplus, which are major retail companies in Korea, are operating large-scale DLCs in Yeoju and Icheon, Korea. CU, GS, and Seven-Eleven, which are major CVS chain companies, are also operating DLCs in Korea. Since DLCs provide logistics services and information optimized for shippers, related market is continuously expanding with online, fresh food, and shoes DLCs. In this context, measuring and analyzing the efficiency of DLCs, which is the most widely used performance measure (Andrejić et al., 2016), is important to improve the logistics service and competitiveness of retail DLCs.

Under this background, this paper aims to drive improvement policies for DLCs by analyzing the efficiency of Mart, SSM, and CVS DLCs. To do this, we analyze the efficiencies of operation, finance, and service, and the overall efficiency of the DLCs using data of a distribution company. The case company operates a third party logistics type of DLC that tailors services for each retail type. For this analysis, we use the DEA (data envelopment analysis) model, which is a representative instrument for analyzing efficiency. Also, the causes of the efficiency differences are identified through the logistics characteristics of DLCs.

Research on efficiency analysis has been conducted in various fields. For example, Yoo (2012) analyzed the efficiency

\footnotetext{
* Asia Pacific School of Logistics, Inha University, 100 Inha-ro, Nam-gu, Incheon, 22212, Korea; Email: hwa-joong.kim@inha.ac.kr
} 
of urban railway operations and Lee and Kim (2007) measured the efficiency of Internet companies. Chen et al. (2018) also used efficiency analysis for benchmarking of schools. A thorough review of previous studies on DEA can be found in Emrouznejad et al. (2008), Liu et al. (2013a, b), Kao (2014), and Mariz (2018). In this section, we review previous research on retail types and logistics centers that are most relevant to this study.

First, previous studies on the efficiency of retail types are as follows. Rhonda et al. (1998) conducted DEA analysis by weighting variables to analyze the efficiency of distribution stores. Input variables included labor, experience, store operations cost, and inventory reduction rate. Output variables were sales and net profit. Kim et al. (1999) proposed the improvement goals of inefficient discount stores by analyzing the efficiency of eleven Marts in Korea using DEA. The input variables included store area, opening cost, population density, and income level, while the output variable was sales. Hean et al. (2003) used multiple DEAs to measure distribution efficiency. Input variables included capital, manpower, intermediate variables, accessibility, assortment, arrival rate, information volume, store environment, and operating variables. Kim and Yoo (2014) measured the efficiency of Mart, SSM, and department stores. Input variables were store area, parking lot size, number of employees, and management cost. The output variables included the number of visiting customers per day and sales. Yoo and Ju (2014) used the DEA-Window model to measure the efficiency of the Busan retail industry. Input variables included the number of employees, cost of goods sold, and building floor area. Kim and Kim (2015) analyzed the relative efficiency of CVS, tele-commerce, e-commerce, SSM, and department stores using DEA and Malmquist productivity analysis techniques. Input variables were wages, management expenses, variable costs, and fixed costs, while output variables included sales and operating profit.

In addition, previous research on the efficiency analysis of logistics centers are as follows. Jukka et al. (2007) measured the efficiency of different warehouses for warehouse selection by combining AHP (analytic hierarchy process) and DEA. Input variables were direct cost and overhead cost, while output variables included time, quality, reliability of quantity, storage ability, and flexibility for rush order handling. Lim (2008) used multilevel DEA models to measure the operation, service quality, and profitability of logistics centers and proposed a benchmarking model to improve the efficiency of the inefficient logistics centers. The input variables for the operational efficiency were the number of employees, operational capacity, execution capacity, organizational system, and human resource management. Output variables included operational efficiency and employee satisfaction. The input variables for service efficiency included the number of employees, operational capacity, execution capacity, human resource management, operational efficiency, and employee satisfaction, while output variables were customer satisfaction, customer retention, and cargo increase. The input variables for financial efficiency included the number of employees, operational capacity, executive ability, organizational system, and human resources management. Output variables were sales scale, profitability, return on investment, and payment ability. Park (2012) measured and analyzed the change of efficiency using the DEA window technique and Malmquist productivity analysis technique for the dynamic analysis of the productivity of regional warehouses. Input variables were the number of companies, the number of workers, the number of equipment, and the number of warehouses. The output variable was sales.

Some previous studies have focused on the efficiency analysis of retail types and logistics centers. However, there is no previous research on the effectiveness of the DLC, as the importance of DLCs on retail types has recently emerged. In particular, there is no study that compared and analyzed characteristics and operation, finance, and service efficiencies of each retail type to the best of our knowledge. Therefore, this paper makes the academic contribution of analyzing the efficiency of DLCs by collecting operational data of a Korean distribution company, which owns Marts, SSMs, and CVS chains.

This paper consists of four sections. Section 2 explains the analysis method and input and output variables, and Section 3 presents the analysis results, causes of results, and draw implications. Finally, Section 4 summarizes the findings and implications of the study and presents future research directions.

\section{Analysis method and variable selection}

This section describes the DEA models and input and output variables used for the efficiency analysis. Data used in the analysis was collected through interviews and direct visits to two Mart DLCs, four SSM DLCs, and six CVS DLCs of the case company. Since the data used for the analysis includes confidential data, this paper presents only the relative rate (= DLC variable value / minimum variable value) in many cases.

\subsection{DEA model}

The DEA models used in this paper are CCR, BCC, and super-efficiency models. The CCR model is the first DEA model, named after its developer Charnes, Cooper and Rhodes (Charnes et al., 1978). The CCR model is a linear programming model that measures efficiency by determining the weights of input and output variables. Although many subsequent models have been developed, the CCR model is still the most widely used DEA model. The BCC model, named after Banker, Charnes and Cooper (Banker et al. 1984), is a variant of the CCR model, modified by including the constraint that the total weights on variables equals one. Unlike the CCR model assuming constant returns to scale, the 
BCC model allows variable returns to scale. On the other hand, BCC and CCR models have a problem that the efficiency of DLCs cannot be ranked relative to each other. In order to overcome this problem, the super-efficiency model is commonly used. The super-efficiency model estimates efficiency by excluding the DLC (DMU, decision making unit) itself from the model (Kang and Go, 2011). The scale efficiency (SE) is also used to show the relative difference of the efficiency values of CCR and BCC models.

\subsection{Methods and variables for efficiency analysis by sectors}

In this paper, we analyze the efficiency of operations, finance, and service sector of DLCs using simple input-output equations and DEA modelling. Among the sector efficiencies, the operations efficiency is analyzed by separating individual operations efficiencies and overall operations efficiency. The individual operations efficiency is calculated by using individual input and output variables, which are calculated using the simple input-output equation (= output variable value/input variable value).

For these efficiency analyses, input and output variables listed in Table 1(a), were selected as follows. First, input variables for the operations sector were selected as warehouse area, the number workers (NV), and the number of vehicles (NV) according to Kim (1999) and Kim and Yoo (2014). The output variable was selected as the number of delivery points (stores) supported by the DLC. However, since the store sizes differ across CVS, SSM, and Mart, efficiency comparisons across different retail types of DLCs are made after standardizing the variable values. The standardization index (SI) was calculated as the relative sales of logistics services (CVS 1: SSM 1.26: Mart 3.3) over relative numbers of stores nationwide (1: 0.27: 0.069) of the case company. As a result, the SI of CVS is 1, SSM 4.67, and Mart 47.83. The output variable for operations efficiency analysis was the standard number of delivery points obtained by multiplying the number of delivery points and the SI.

Next, variables for the finance sector included logistics cost (LC), sales \& general administrative expenses (SGA), and operating profit (OP) according to Lim (2008), Park (2012), and Yoo (2014). We use these values over sales, i.e., logistics cost rate (=logistics cost over sales), SGA rate (=SGA over sales), and OP rate (=OP over sales), in order to eliminate scale differences between DLCs. Since this data is confidential, we used their relative value compared to the minimum value of the dataset, e.g., an OP rate of a DLC over the minimum OP rate of DLCs. As a result, input variables are relative LC rate and relative SGA rate, and output variables are relative OP rate as given in Table 1(a).

For the service sector, input variables are NW, NV, and relative LC rate according to Lim (2008). Again, we use these values per delivery point in order to eliminate scale differences between DLCs. That is, NW per delivery point, NV per delivery point, and relative LC rate per delivery point. The output variable is selected as the service quality index, which the case company measures annually for shippers. The service quality index is quantified by measuring 70 questionnaire items on service quality management, cleanness management, and safety management.

Table 1. Input and output variables

\begin{tabular}{lll}
\hline Sector & Input variable & Output variable \\
\hline (a) Sector efficiency & & \\
\hline Operations sector & Warehouse area, NW, NV & Standard number of delivery points \\
$\begin{array}{l}\text { Finance sector } \\
\text { Service sector }\end{array}$ & Relative LC rate, Relative SGA rate & Relative OP rate \\
& NW per delivery point, NV per delivery point, & Service quality index \\
\hline \hline (b) Overall efficiency & & \\
\hline & Warehouse area, NW, LC rate & $\begin{array}{l}\text { Standard number of delivery points, Sales, Service } \\
\text { quality index }\end{array}$ \\
\hline
\end{tabular}

\subsection{Methods and variables for the overall efficiency analysis}

We selected six variables in order to minimize correlations between variables and by considering characteristics of ordinary DEA models requiring the number of DMUs (decision making unit) to total two to three times the number of variables. As shown in Table 1(b), input variables include warehouse area, NW, and LC rate, while output variables are the number of standard delivery points, sales, and service quality index.

\section{Analysis result and implications}

\subsection{Sector efficiency: Operation}

This section presents DLC's operations efficiency evaluation results and identifies the causes of the results considering logistics characteristics of each retail type. Implications of results also are drawn. Table 2 summarizes the efficiency results calculated by the simple input-output equation (= output variable value/input variable value). As presented in 
Table 2, the average warehouse area efficiency was CVS DLC 0.483, SSM 0.190, and Mart 0.115. That is, CVS DLC requires the smallest warehouse area versus delivery point (store) while Mart DLC needs the largest area. The average manpower efficiency was Mart DLC 10.620, SSM 8.679, and CVS 7.235, implying that Mart and CVS DLCs require the least and most workers versus delivery point respectively. Finally, the average vehicle efficiency SSM DLC 13.655, Mart 13.561, CVS 8.954. While SSM and Mart DLCs showed similar efficiencies, CVS DLC showed the lowest efficiency.

Table 2. Individual operations sector efficiency result

\begin{tabular}{|c|c|c|c|c|}
\hline \multicolumn{2}{|c|}{ DLC } & \multirow{2}{*}{$\begin{array}{c}\text { Warehouse area efficiency }^{\mathrm{a}} \\
0.116\end{array}$} & \multirow{2}{*}{$\frac{\text { Manpower efficiency }^{\mathrm{b}}}{11.202}$} & \multirow{2}{*}{$\frac{\text { Vehicle efficiency }^{\mathrm{c}}}{11.634}$} \\
\hline & A & & & \\
\hline Mart & B & 0.113 & 10.038 & 15.488 \\
\hline & Avg. & 0.115 & 10.620 & 13.561 \\
\hline \multirow{5}{*}{ SSM } & C & 0.218 & 11.008 & 14.854 \\
\hline & D & 0.135 & 5.234 & 13.798 \\
\hline & $\mathrm{E}$ & 0.185 & 8.925 & 13.849 \\
\hline & $\mathrm{F}$ & 0.222 & 9.551 & 12.162 \\
\hline & Avg. & 0.190 & 8.679 & 13.655 \\
\hline \multirow{7}{*}{ CVS } & $\mathrm{G}$ & 0.529 & 6.006 & 7.640 \\
\hline & $\mathrm{H}$ & 0.464 & 7.019 & 10.243 \\
\hline & I & 0.483 & 7.824 & 10.339 \\
\hline & $\mathrm{J}$ & 0.463 & 7.089 & 10.459 \\
\hline & $\mathrm{K}$ & 0.553 & 7.882 & 8.171 \\
\hline & $\mathrm{L}$ & 0.407 & 7.593 & 6.874 \\
\hline & Avg. & 0.483 & 7.235 & 8.954 \\
\hline
\end{tabular}

${ }^{a}$ Number of standard delivery points/Warehouse area

${ }^{\mathrm{b}}$ Number of standard delivery points/Number of workers

${ }^{\mathrm{c}}$ Number of standard delivery points/Number of vehicles

Next, overall operations efficiency evaluation results are summarized in Table 3. The results of the CCR model showed that the operations efficiencies of Mart DLCs are all 1 and those of SSM and CVS DLCs range from 0.922 1 and 0.924 1 respectively. The results of the BCC model showed that the operations efficiency of Mart and SSM DLCs are all 1 and those of CVS DLCs range from 0.954 1. These results indicate that Mart DLC's operations efficiency is the highest and DLCs within the same retail type have slightly different operations efficiencies. The scale efficiency result also shows that DLCs within the same retail type have slightly different operations efficiencies. However, the ANOVA analysis result on the operations efficiencies between DLCs of retail types found the $f$-value $=1.376$ and $p$-value $=0.206$, which indicates that there is no significant difference between retail types. In summary, there are slight differences between DLCs within the same retail type, but no significant difference between retail types.

Now, we further analyze the results of Tables 2 and 3 by presenting plausible reasons for results considering operational characteristics of retail types. First, Mart DLC has the lowest warehouse area efficiency while featuring the highest manpower and vehicle efficiencies. The result can be attributed to logistics characteristics of Mart DLCs. Mart DLCs have a high automation rate by handling bulk orders via pallets. The warehouse area efficiency is low because such automation requires warehouses with large space, e.g., sorter and marshalling space, to handle large cargoes. However, Mart DLCs have high manpower efficiency due to automated and standardized procedures, as well as high vehicle efficiency because they utilize TMS (transport management systems) to optimize loading operations and transportation routes. Second, CVS DLCs showed the opposite results to Mart DLCs.

Table 3. DEA analysis result for the overall operations efficiency

\begin{tabular}{|c|c|c|c|c|}
\hline \multicolumn{2}{|c|}{ DLC } & CCR model & BCC model & $\mathrm{SE}$ \\
\hline \multirow{3}{*}{ Mart } & A & 1 & 1 & 1 \\
\hline & B & 1 & 1 & 1 \\
\hline & Avg. & 1 & 1 & 1 \\
\hline \multirow{5}{*}{ SSM } & $\mathrm{C}$ & 1 & 1 & 1 \\
\hline & $\mathrm{D}$ & 0.904 & 1 & 0.904 \\
\hline & $\mathrm{E}$ & 0.918 & 1 & 0.918 \\
\hline & $\mathrm{F}$ & 0.865 & 1 & 0.865 \\
\hline & Avg. & 0.922 & 1 & 0.922 \\
\hline \multirow{7}{*}{ CVS } & $\mathrm{G}$ & 0.956 & 1 & 0.956 \\
\hline & $\mathrm{H}$ & 0.874 & 0.942 & 0.928 \\
\hline & I & 0.953 & 1 & 0.953 \\
\hline & $\mathrm{J}$ & 0.879 & 0.892 & 0.985 \\
\hline & $\mathrm{K}$ & 1 & 1 & 1 \\
\hline & $\mathrm{L}$ & 0.880 & 0.891 & 0.988 \\
\hline & Avg. & 0.924 & 0.954 & 0.963 \\
\hline
\end{tabular}


That is, the manpower and vehicle efficiencies of CVS DLC are the lowest while its warehouse area efficiency is the highest. The manpower efficiency of CVS DLCs is low because CVS DLCs are operated in a labor-intensive manner to fulfill small and frequent orders via box and individual items from CVSs. The vehicle efficiency of CVS DLS is also low because the possibility of LTL (less-than-truck load) delivery is high due to the need to process orders for small quantities and lots of vehicles.

However, the warehouse area efficiency of CVS DLC is high because most warehouses are manually operated, so there is no need for large-scale automated facilities. Third, the operations efficiency of SSM DLCs is intermediate among Mart and CVS DLCs because SSM DLCs have intermediate logistics characteristics. In detail, SSM stores generally operate a small-sized warehouse that can hold only high-demand items delivered using pallets and FTL (full-truck load) delivery. SSM also uses LTL delivery using roll containers like CVS for low-demand items. For warehouse area, manpower and vehicle efficiencies, SSM DLC is intermediate among Mart and CVS DLCs by using semi-automatic equipment such as small picker, DAS (digital assorting system) and DPS (digital picking system), roll containers, pallets, and medium-sized TMS.

Finally, we derive implications on improving the competitiveness of DLCs from the above operational characteristics and efficiency evaluation results as follows:

- Mart DLCs need to maximize manpower and vehicle efficiencies as well as improve warehouse area efficiency to avoid excessive automation and to reduce initial investment costs through optimizing the use of automation equipment.

- CVS DLCs need to improve vehicle efficiency by forecasting cargo amounts and to increase manpower efficiency through picking and sorting operations with the help of PDAs (personal digital assistant).

- SSM DLCs need to optimize picking and sorting systems to maintain high warehouse efficiency compared to Mart DLCs, and to improve manpower and vehicle efficiencies, e.g., by predicting the quantity of roll containers.

Table 4. Variable values for the finance efficiency

\begin{tabular}{|c|c|c|c|c|}
\hline \multirow{2}{*}{\multicolumn{2}{|c|}{ DLC }} & \multicolumn{2}{|c|}{ Input variable } & \multirow{2}{*}{$\begin{array}{l}\text { Output variable } \\
\text { Relative OP rate }\end{array}$} \\
\hline & & Relative LC rate & Relative SGA rate & \\
\hline \multirow{3}{*}{ Mart } & A & & & 10.61 \\
\hline & B & 1 & & 17.13 \\
\hline & Avg. & 1.04 & 1.65 & 13.87 \\
\hline \multirow{5}{*}{ SSM } & $\mathrm{C}$ & 1.15 & & 2.76 \\
\hline & $\mathrm{D}$ & 1.02 & & 5.26 \\
\hline & $\mathrm{E}$ & 1.11 & & 4.69 \\
\hline & $\mathrm{F}$ & 1.16 & & 1.93 \\
\hline & Avg. & 1.11 & 2.33 & 3.66 \\
\hline \multirow{7}{*}{ CVS } & $\mathrm{G}$ & & 1 & 7.91 \\
\hline & $\mathrm{H}$ & & 1 & 5.02 \\
\hline & I & 1.12 & 1.62 & 6.54 \\
\hline & $\mathrm{J}$ & 1.07 & 1.90 & 9.84 \\
\hline & K & 1.21 & 1.31 & 1 \\
\hline & $\mathrm{L}$ & 1.19 & & 1.70 \\
\hline & Avg. & 1.15 & 1.40 & 5.34 \\
\hline
\end{tabular}

\subsection{Sector efficiency: Finance}

This section first describes the analysis results of finance efficiency shown in Table 4. The relative logistics cost (LC) rate was in the order of SVS DLC 1.15, SSM 1.11, and Mart 1.04, and the relative SGA rate in the order of SSM DLC 2.33, Mart 1.65, and CVS 1.4. The relative operations profit (OP) rate was in the order of Mart DLC 13.22, CVS 5.11 and SSM 3.50. The DEA results in Table 5 show that financial efficiency is highest in Mart, followed by CVS and SSM DLCs. SE is lowest in Mart, followed by SSM and CVS DLCs. However, the ANOVA analysis result showed that there was no significant difference between retail type DLCs, with the $f$-value $=2.051$ and $p$-value $=0.184$.

The results of Table 4 and Table 5 are analyzed according to the retail type and reasons accounting for these results are estimated by considering the characteristics of corresponding DLCs are as follows. First, Mart DLCs showed a relatively high OP and low logistics cost rate. This is because, as described above, Mart DLCs have high vehicle and manpower efficiencies due to automation and standardization, and services large-scale delivery points, i.e., Marts feature economies of scale. However, Mart DLCs require high initial installation costs such as a large warehouse area, automation and large-scale facilities, which is a high barrier to market entry. Second, SSM DLCs have a lower OP margin than CVS DLC, which implies a high SGA as shown in Table 4. This result means that labor costs and expenses are high because Mart DLCs operate an automated warehouse in the form of a transport center, while SSM DLCs operate in a combination of distribution and transport centers. There are also additional requirements for products to be repackaged from a pallet to a roll container or processed separately. In terms of manpower management, Mart DLCs employ a small number of managers due to its high rate of automation, while CVS DLCs mainly use short-term workers. Third, SSM DLCs have a 
higher proportion of long-term management personnel than short-term personnel in order to maintain an intermediate automated system. This is another characteristic of SSM DLCs that are located at the intermediate point between Mart and CVS DLCs as described above. The following are ways to improve the competitiveness of DLCs, which are derived from financial characteristics and efficiency evaluation results:

- Mart DLCs should identify ways to shorten the payback period of the initial installation cost by locating DLCs at a low land-price area such as local government logistics development districts and reduce logistics and SGA expenses by standardizing tasks.

- CVS DLCs should employ strategies focusing on the reduction of service and rental fees in order to overcome high logistics cost.

- SSM DLCs need to consider ways to reduce its high SGA expenses by outsourcing high cost tasks, excluding activities associated with core competitiveness.

Table 5. DEA analysis results for the finance efficiency

\begin{tabular}{|c|c|c|c|c|}
\hline \multicolumn{2}{|c|}{ DLC } & CCR model & BCC model & SE \\
\hline \multirow{3}{*}{ Mart } & A & 0.961 & 1 & 0.961 \\
\hline & B & 1 & 1 & 1 \\
\hline & Avg. & 0.981 & 1 & 0.981 \\
\hline \multirow{5}{*}{ SSM } & $\mathrm{C}$ & 0.88 & 0.896 & 0.982 \\
\hline & $\mathrm{D}$ & 0.982 & 1 & 0.982 \\
\hline & E & 0.904 & 1 & 0.904 \\
\hline & $\mathrm{F}$ & 0.879 & 0.898 & 0.979 \\
\hline & Avg. & 0.911 & 0.949 & 0.962 \\
\hline \multirow{7}{*}{ CVS } & G & 1 & 1 & 1 \\
\hline & $\mathrm{H}$ & 0.974 & 1 & 0.974 \\
\hline & I & 0.928 & 1 & 0.928 \\
\hline & $\mathrm{J}$ & 0.936 & 1.000 & 0.936 \\
\hline & $\mathrm{K}$ & 0.918 & 0.945 & 0.971 \\
\hline & $\mathrm{L}$ & 0.903 & 0.959 & 0.942 \\
\hline & Avg. & 0.943 & 0.984 & 0.959 \\
\hline
\end{tabular}

\subsection{Sector efficiency: Service}

Table 6 summarizes the input and output variables for estimating service efficiency, and Table 5 summarizes DEA analysis results. As shown in Table 6, the manpower and vehicle per delivery point of Mart DLC were 0.094 workers and 0.096 vehicles on average, those of SSM DLC were 0.124 and 0.073 , and those of CVS DLC 0.139 and 0.115 , respectively. That is, CVS DLCs require more manpower and vehicles to support one delivery point (store). The logistics cost of CVS DLCs were relatively high as the relative LC rate of Mart DLC was 1.042, SSM DLC was 1.111, and CVS DLC was 1.151 on average.

Table 6. Variable values for the service efficiency

\begin{tabular}{|c|c|c|c|c|c|}
\hline \multirow{2}{*}{\multicolumn{2}{|c|}{ DLC }} & \multicolumn{3}{|c|}{ Input variable } & \multirow{2}{*}{$\begin{array}{c}\text { Output variable } \\
\text { Service quality index }\end{array}$} \\
\hline & & NW per delivery point & NW per delivery point & Relative LC rate & \\
\hline \multirow{3}{*}{ Mart } & A & 0.089 & 0.860 & 1.082 & 85.02 \\
\hline & B & 0.100 & 0.065 & 1.000 & 85.41 \\
\hline & Avg. & 0.094 & 0.075 & 1.041 & 85.21 \\
\hline \multirow{5}{*}{ SSM } & $\mathrm{C}$ & 0.091 & 0.670 & 1.150 & 79.21 \\
\hline & $\mathrm{D}$ & 0.191 & 0.730 & 1.018 & 88.52 \\
\hline & $\mathrm{E}$ & 0.112 & 0.720 & 1.106 & 88.11 \\
\hline & $\mathrm{F}$ & 0.105 & 0.820 & 1.162 & 81.51 \\
\hline & Avg. & 0.124 & 0.073 & 1.110 & 84.31 \\
\hline \multirow{7}{*}{ CVS } & $\mathrm{G}$ & 0.166 & 0.131 & 1.152 & 78.72 \\
\hline & $\mathrm{H}$ & 0.142 & 0.980 & 1.182 & 79.71 \\
\hline & I & 0.128 & 0.970 & 1.126 & 79.12 \\
\hline & $\mathrm{J}$ & 0.141 & 0.960 & 1.069 & 82.12 \\
\hline & $\mathrm{K}$ & 0.127 & 0.122 & 1.209 & 73.02 \\
\hline & $\mathrm{L}$ & 1.132 & 0.146 & 1.186 & 88.11 \\
\hline & Avg. & 0.139 & 0.115 & 1.154 & 80.11 \\
\hline
\end{tabular}


The service quality index of Mart DLC was 85.21, SSM DLC was 84.31, and CVS DLC was 80.11. DEA analysis results shown in Table 7 found the service efficiency of Mart DLC was 1, SSM DLC was 0.947, and CVS DLC was 0.812 on average. In addition, the ANOVA analysis result showed that there was a statistically significant difference in the service efficiency between DLCs of each retail types with the f-value $=10.113$ and $\mathrm{p}$-value $=0.0049$.

Table 6. Variable values for the service efficiency

\begin{tabular}{cccccc}
\hline \multirow{2}{*}{ DLC } & & \multicolumn{3}{c}{ Input variable } & $\begin{array}{c}\text { Output variable } \\
\text { Service quality index }\end{array}$ \\
\cline { 3 - 5 } Mart & NW per delivery point & NW per delivery point & Relative LC rate & 85.02 \\
& A & 0.089 & 0.860 & 1.082 & 85.41 \\
& B & 0.100 & 0.065 & 1.000 & 85.21 \\
\hline \multirow{6}{*}{ SSM } & Avg. & 0.094 & 0.075 & 1.041 & 79.21 \\
& C & 0.091 & 0.670 & 1.150 & 88.52 \\
& D & 0.191 & 0.730 & 1.018 & 88.11 \\
& E & 0.112 & 0.720 & 1.106 & 81.51 \\
& F & 0.105 & 0.820 & 1.162 & 78.31 \\
\hline \multirow{6}{*}{ CVS } & Avg. & 0.124 & 0.073 & 1.110 & 79.71 \\
& G & 0.166 & 0.131 & 1.152 & 79.12 \\
& H & 0.142 & 0.980 & 1.182 & 82.12 \\
& I & 0.128 & 0.970 & 1.126 & 73.02 \\
& J & 0.141 & 0.960 & 1.069 & 88.11 \\
& K & 0.127 & 0.122 & 1.209 & 80.11 \\
\hline
\end{tabular}

The following analyzes and discusses the service efficiency evaluation results shown in Tables 6 and 7 and the reasons for these results considering the characteristics of DLCs. In the case of Mart DLCs with the highest service efficiency, a Mart has a warehouse of a certain size and can hold sufficient stock for about $2 \sim 3$ days of product demand. Therefore, the manager of the Mart may experience a wide range of logistics service failures such as non-delivery and misdelivery. On the other hand, in case of CVS DLCs with the lowest service efficiency, CVSs do not have their own warehouses, so there is a high possibility of stock-outs. Especially, due to the nature of CVS where one person is usually working, the demand level for delivery on time (within 30 minutes) is high for checking delivered items to minimize time consumption. Another reason is that the CVS owners' room for the service failure is narrow.

The implications of this analysis results are as follows. CVS DLCs need to provide a more advanced delivery system and more optimized delivery algorithm than Mart DLCs for higher service competitiveness. Especially, this step is required to establish measures to recover from service failure such as non-delivery or misdelivery. To improve competitiveness in the service sector, a picking and sorting system with pre-store arrival notification service, categorization of products, and personal mobile phone applications, a carrier-incentive to improve the last mile service, a web-based comment system, and increasing the profit of CVS owners through courier services using reverse logistics are needed.

Table 7. DEA analysis result for the service efficiency

\begin{tabular}{|c|c|c|c|c|}
\hline \multicolumn{2}{|c|}{ DLC } & CCR model & BCC model & SE \\
\hline \multirow{3}{*}{ Mart } & A & 1 & 1 & 1 \\
\hline & B & 1 & 1 & 1 \\
\hline & Avg. & 1 & 1 & 1 \\
\hline \multirow{5}{*}{ SSM } & $\mathrm{C}$ & 0.986 & 1 & 0.986 \\
\hline & $\mathrm{D}$ & 1 & 1 & 1 \\
\hline & E & 0.932 & 1.000 & 0.932 \\
\hline & $\mathrm{F}$ & 0.869 & 0.934 & 0.930 \\
\hline & Avg. & 0.947 & 0.984 & 0.962 \\
\hline \multirow{7}{*}{ CVS } & $\mathrm{G}$ & 0.793 & 0.891 & 0.890 \\
\hline & $\mathrm{H}$ & 0.789 & 0.903 & 0.874 \\
\hline & I & 0.821 & 0.897 & 0.915 \\
\hline & $\mathrm{J}$ & 0.895 & 0.933 & 0.959 \\
\hline & $\mathrm{K}$ & 0.707 & 0.828 & 0.854 \\
\hline & $\mathrm{L}$ & 0.868 & 0.999 & 0.869 \\
\hline & Avg. & 0.812 & 0.909 & 0.894 \\
\hline
\end{tabular}




\subsection{Overall efficiency by retail types}

This section presents the evaluation results of the overall efficiency of DLCs, which are summarized in Table 8. Note that a super-efficiency model is considered in the evaluation because the discriminatory power of CCR and BCC models can be limited in the presence of high specialization among DMUs. Such a problem can be found in Table 8 in that the efficiency scores of all DLCs under CCR and BCC models were evaluated as 1 (one). Considering results shown in Tables 2 7, this result implies that each of the DLCs developed its own operational characteristics in accordance with the availability of managerial resources and market environments. That is, a series of benchmarking approaches to improve the efficiencies of DLCs can be myopic without considering in-depth understanding of managerial issues for each DLC.

From the perspective of the super-efficiency model, Mart DLC featured the highest super-efficiency at 159.0 on average. Meanwhile, the super-efficiency scores of SSM and CVS DLCs were identified as 123.3 and 110.6 on average, respectively. This result indicates that the super-efficiency model can be used for finding potential efficiency improvements for SSM and CVS DLCs. For example, in case of the service sector efficiency, Mart DLCs had more options for increasing the order filling rate by taking advantage of ample storage space to hold more inventories to respond to customer demands. However, such inventory and customer order management cannot be directly implemented in CVS DLCs because of the lack of workers and storage capacity. In this situation, a manager can make investment decisions for expanding capacities of manpower and storage with the objective of increasing efficiency in the service sector. It should be noted that the efficiency differences between DLCs for different retail types may not be significant because the result of the ANOVA analysis did not reach statistical significance as the $p$-value $=0.165$.

Table 8. DEA analysis result for the overall efficiency

\begin{tabular}{cccccc}
\hline \multicolumn{2}{c}{ DLC } & CCR model & BCC model & SE & Super efficiency \\
\hline \multirow{4}{*}{ Mart } & A & 1 & 1 & 1 & 209.1 \\
& B & 1 & 1 & 1 & 109.0 \\
& Avg. & 1 & 1 & 1 & 159.0 \\
\hline \multirow{6}{*}{ SSM } & C & 1 & 1 & 1 & 114.2 \\
& D & 1 & 1 & 1 & 138.2 \\
& E & 1 & 1 & 1 & 129.7 \\
& F & 1 & 1 & 1 & 111.1 \\
& Avg. & 1 & 1 & 1 & 123.3 \\
\hline \multirow{6}{*}{ CVS } & G & 1 & 1 & 1 & 147.4 \\
& H & 1 & 1 & 1 & 100.2 \\
& I & 1 & 1 & 1 & 102.1 \\
& J & 1 & 1 & 1 & 105.7 \\
& K & 1 & 1 & 1 & 105.5 \\
& L & 1 & 1 & 1 & 110.6 \\
\hline
\end{tabular}

\section{Conclusion}

This paper estimated operations, finance, and service sectors' efficiencies for Mart, SSM, and CVS DLCs in a Korean distribution company. Subsequently, we identified efficiency differences between retail types resulting from intrinsic characteristics of DLCs and derived managerial implications for efficiency improvements. The estimation results can be summarized as follows. CVS DLCs showed the highest warehouse area efficiency and Mart DLCs showed the highest efficiency of the number of workers and vehicles. In terms of financial efficiency, Mart DLCs showed high operating profit due to low logistics cost, SSM DLCs had high SGA cost, and CVS DLCs had high logistics cost. From the perspective of service efficiency, Mart DLCs showed better efficiency than other DLCs. Finally, there was no difference in the overall efficiency between retail types.

Given these results, several strategic approaches for efficiency improvements can be stated. First, according to the overall operations efficiency from CCR and BCC models, we can say that a series of efforts for improving DLCs' operations efficiency should be aligned with logistics characteristics. More specifically, each DLC is likely to be confronted with different managerial resources and market environments. These differences require a customized efficiency improvement strategy for the DLC. Second, efficiency analysis can be a viable method to identify efficiency improvements for DLCs. This is because such an approach can expose both strengths and weaknesses of operational aspects of DLCs. For example, Mart DCLs can achieve higher efficiency in the operations sector by means of increasing storage density of warehouses. Furthermore, for CVS DLCs, improvements in vehicle efficiency with effective forecasting of product demand and in manpower efficiency with high-performing picking and sorting systems can be viable strategies. Finally, for SSM DLCs, a systematic approach to efficiently managing picking and sorting systems is a 
critical issue to maintain lower SGA cost in practice.

A brief discussion of future research directions can be given as follows. First, our findings can be extended by considering operations efficiencies of DLCs in different retail companies. Second, a study on the operational efficiency of e-commerce DLCs can be meaningful. Third, a series of comparison analyses between DLCs in public and private sectors, e.g., efficiency comparison between military and civilian DLCs, should be a focus for further investigation.

\section{Acknowledgements}

This work was supported by INHA UNIVERSITY Research Grant.

\section{References}

Andrejić, M., Bojović, N., Kilibarda, M., 2016. A framework for measuring transport efficiency in distribution centers. Transport Policy 45, 99-106.

Banker, R.D., Charnes, A., Cooper, W.W., 1984. Some models estimating technical and scale inefficiencies in data envelopment analysis. Management Science 30, 1078-1092.

Charnes, A., Cooper, W.W., Rhodes, E.L., 1978. Measuring the efficiency of decision making units. European Journal of Operational Research 2, 429-444.

Chen, H.K., Lin, Y.H., Yih, J.M., 2017. Comparisons on the benchmarking of school efficiency based on SFA and DEA. International Journal of Intelligent Technologies and Applied Statistics 10, 207-220.

Emrouznejad, A., Parker, B.R, Tavares, G., 2006. Evaluation of research in efficiency and productivity. Economic Planning Sciences 42, 151-157.

Hean, K., Chub, S., 2003. Retail productivity and scale economies at the firm level: A DEA approach. Omega 31, 75-82.

Jukka, K.J., Lehmusvaarab, A., Nisonenc, J., 2007. Warehouse operator selection by combining AHP and DEA methodologies. International Journal of Production Economics 108, 135-142.

Kao, C., 2014. Network data envelopment analysis: A review. European Journal of Operational Research 239, 1-16.

Kim, T.-U., Lim, Y.-L., Kim, Y.-G., 1999. Evaluating efficiency of Korean mass discount stores: A case study. Korean Management Science Review 16, 1-11.

Kim, G., Khoe, K.-I., 2011. A study on managerial efficiency of global IDM semiconductor suppliers: Based on super efficiency DEA by scale categorization. Korean Journal of Business Administration 25, 369-394.

Kim, C.-K., Kim, J.-W., 2015. A study on the relative efficiency of retail industry in Korea. Research of Retail 20, 33-45.

Kim, S.-H., Yoo, B.-K., 2014. An analysis of retail business efficiency in Korea. Journal of Distribution Science 12, 23-30.

Ko, K.-K., 2017. Theory of Efficiency Analysis: Data Envelopment Analysis and Stochastic Frontier Analysis. MoonWooSa, Goyang.

Leam, B.-H., 2008. Using BSC and multi-stage DEA to develop a benchmarking model on the productivity of logistics centers. Korea Logistics Review 18, 201-225.

Lee, K.-J., Kim, J.-J., Cho, G., 2007. The evaluation of the efficiency of internet companies using a DEA model. Korean Journal of Business Administration 20, 109-136.

Liu, J.S., Lu, L.Y.Y., Lu, W.M., Lin, B.J.Y., 2013a. A survey of DEA applications. Omega 41, 893-902.

Liu, J.S., Lu, L.Y.Y., Lu, W.M., Lin, B.J.Y., 2013b. Data envelopment analysis 1978-2010: A citation-based literature survey. Omega 41, 3-15.

Mariz, A., 2018. A review of dynamic data envelopment analysis: State of the art and applications. International Transactions in Operational Research 25, 469-505.

Park, H.-G., 2012. The productivity analysis on regional logistics warehouse. Journal of Korea Port Economic Association 28, 143157.

Rhonda, R., Richard, S., William, L., John, W., 1993. A process for evaluating retail store efficiency: A restricted DEA approach. International Journal of Research in Marketing 15, 487-503.

Ryu, S.-J., 2015. The Vein of Distribution: Retail Industry and Status. Seoul, Korea Productivity Center.

Yoo, G.-S., Kim, S.-J., 2012. A study on the operational efficiency of urban railway system based on data envelopment analysis. Seoul Studies 13, 237-246.

Yoo, Y.-M., Joo, S.-H., 2014. Using DEA/Window analysis to measure the relative efficiency of distribution industry in Busan over times. Journal of Regional Studies 22, 265-284. 